\title{
Evaluation of Anterior Alveolus Morphology in Different Facial Growth Patterns
}

Tarulatha R Shyagali ${ }^{1}$, Shweta Dixit ${ }^{2}$

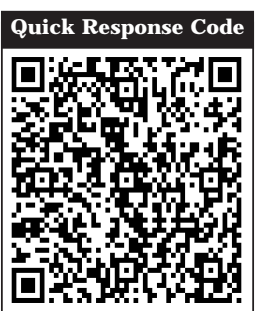

doi: 10.5866/2016.8.10155

1Professor and Head of the Department, Department of Orthodontics and Dentofacial Orthopedics,

Hitkarini Dental College and Hospital, J abalpur

2Senior lecturer,

Department of Orthodontics and Dentofacial

Orthopedics,

Darshan Dental College and Hospital, Udaipur.

\section{Article Info:}

Received: J uly 11, 2016

Review Completed: August 10, 2016

Accepted: September 11, 2016

Available Online: December, 2016 (www.nacd.in) (C) NAD, 2016 - All rights reserved

\section{Email for correspondence:}

drtarulatha@gmail.com

\begin{abstract}
:
Background: Thestudy was aimed to evaluatetheanterior alveolar anatomy variation in different growth patterns.

Materials and Methods: The cross sectional study included hundred pretreatment lateral cephalograms. The lateral cephal ograms were sorted into class I, class II and class III groups and each group was again divided into low, average and high angle case. Each lateral cephalogram was traced for the upper anterior alveolar width (UAAW), Upper posterior alveolar width (UPAW), Lower anterior alveolar width (LAAW), lower posterior alveolar width (LPAW), upper alveolar height (UAH) and lower alveolar height $(\mathrm{LAH})$. The collected data was statistically analyzed for the difference between the different groups using ANOVA.

Results: Significant difference was noted for the lower posterior alveolar bone thickness for the class I and class II group. Highly significant difference was noted between the average and the low mandibular divergence groups for the measurements like UAH and UPAW. Significant difference was seen in between the low and average mandibular divergence group for the measurements $U A H$ and UPAW. Between averageand high mandibular divergencegroup the highly significant difference was noted for LAH.

Conclusion: Both the sagittal and the vertical skeletal relationship significantly effects the anterior alveolar anatomy. Clinician needs to be aware of these differences in order to provide the best possible treatment plan and the prognosis without the iatrogenic damage to the teeth and the alveolar bone.
\end{abstract}

Key words: Alveolar bone thickness, malocclusion, mandibular divergence, Class I, Class II, Class III.

\section{Introduction}

Orthodontist is no magician to bring the teeth into alignment without the support of the anatomy and the physiology underlying. However, the anatomy sometimes can constitute a limitation for the orthodontic tooth movement and the same has been explained by the ven-diagram of Envelop of discrepancy by Ackermann and Proffit which literally gives the bird's eye view of the possibilities of tooth movement in all the dimensions. ${ }^{1}$

Sound knowledge of anatomy and the cellular biology is must for an orthodontist to diagnose and treat a case in a physiologically sound manner. M ost of the earlier studies which dealt with the 
anatomical constraints have stressed the limitation to the orthodontic tooth movement. ${ }^{2-9}$ The possibilities of iatrogenic damage by the orthodontic treatment are high in case of the scanty alveolar bone thickness.

The well versed damage includes the gingival recession, the wash board appearance, fenestrations and dehiscence and the root resorption. ${ }^{10-16}$ The best way to address such problems is to prevent such problems from budging up. For so much so as to the prevention is better than cure, one has to know the alveolar bone anatomy in different malocclusions and growth pattern. With this as a background the present study was aimed to assess the alveolar bone thickness in the Indian adults who required orthodontic treatment.

\section{Materials and Methods}

A cross sectional study was conducted in the department of orthodontics and dentofacial orthopedics. Ethical clearance for the study was obtained by the institutional ethical committee. The pretreatment lateral cephal ograms of hundred adult patients were retrieved from the record section of the department. Age of the sample ranged from 1835 years. All the lateral cephalograms were taken in the centric occlusion using the standard protocol in natural head position. The cephalograms were traced for the standard sagittal skeletal parameters (Table 1) and were grouped into class I, class II and class III categories. Each category was traced again for the standard vertical parameters (Table 1) and was regrouped intolow, average and high angle class I, class II and class III cases respectively. Finally, thelateral cephalograms were traced for the anterior alveolar anatomy of the upper and lower jaw using the parameters suggested in the earlier study of similar kind by Handelman (1996) ${ }^{8}$ and the same is represented in figure 1.

1. UAH: bone superior to the upper incisors. Measured from the upper incisor root tip to the palatal plane

2. LAH: bone inferior to the lower incisors. Measured from the lower incisor root tip to the tangent to the lowest point on the symphysis which is parallel to the occlusal plane

3. UAAW: bone anterior to the upper incisor. Measured from the upper root apex to the labial cortical plate along the plane parallel to the palatal plane
4. UPAW: bone posterior to the upper incisor. Measured from the upper root apex to the palatal cortical plate along the plane parallel to the palatal plane

5. LAAW: bone anterior to the lower incisors. Measured from the lower incisor root tip to the labial cortical plate along the plane drawn through the lower incisor apex parallel to the occlusal plane.

6. LPAW: bone posterior to the lower incisors. Measured from the lower incisor root tip to the labial cortical plate along the plane drawn through the lower incisor apex parallel to the occlusal plane.

The collected data was tabulated and was subjected to descriptive statistical analysis using SPSS 15. One way ANOVA was applied to check the difference of alveolar bone morphology between different groups of malocclusions and the different growth patterns.

\section{Results}

Table 2 represents the sample division into class I, II and III with respective mandibular divergence. Comparatively class III malocdusion sample was less. The alveolar bone measurements are depicted in table $3 \mathrm{~A}$ for different malocclusion groups and the $p$-value for the malocdusion groups is shown in table 3B. The results show that there existed significant difference between class I and class II malocclusion for the lower posterior alveolar bone thickness.

The table 4A and 4B represent the different alveolar bone measurements for the different mandibular divergence groups and their p-value respectively. There existed a highly significant difference for the height of the upper alveolar bone and the upper posterior alveolar bone thickness between the low and average mandibular divergence groups. Whereas, for the low and high mandibular divergence groups, highly significant difference ( $p<0.001$ ) was found for the upper and lower alveolar bone height; the upper and lower posterior alveolar bone thickness. For the average and high mandibular divergence group the highly significant difference was noted only for lower alveolar bone height. 


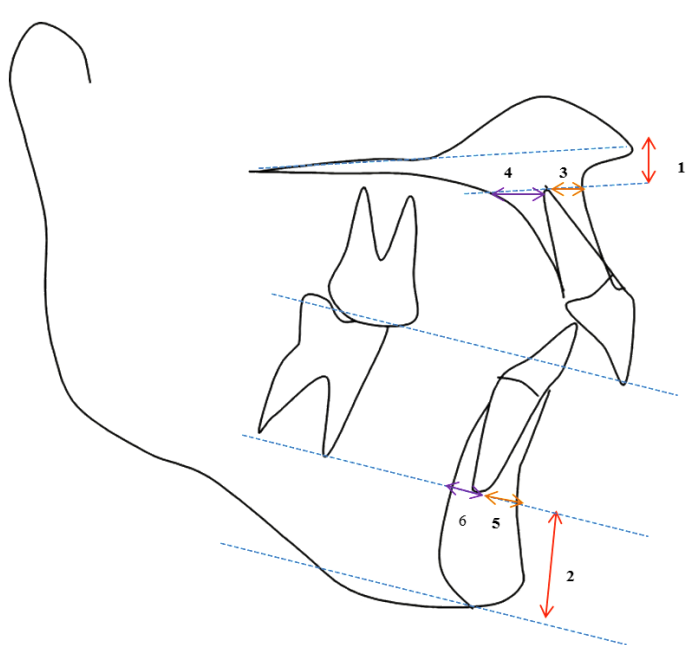

Figure 1: Measurements used for Measuring the Alveolar

Width of Maxilla and Mandible

\section{Discussion}

The main objective of the study was to explore the natural morphological constraints for the effective orthodontic tooth movement. In the earlier literature same constraints were termed as "orthodontic walls" and the term seems to be rightly coined for the way we orthodontist are bound to these constraints. ${ }^{8}$

Many a time's cases with thin alveolar bone will be presented to orthodontists (Figure2), which pose challenge in deciding the treatment plan. Certain cases will be presented with the visibility of the root prominence (wash board appearance) because of the alveolar bone thinness and such cases if treated
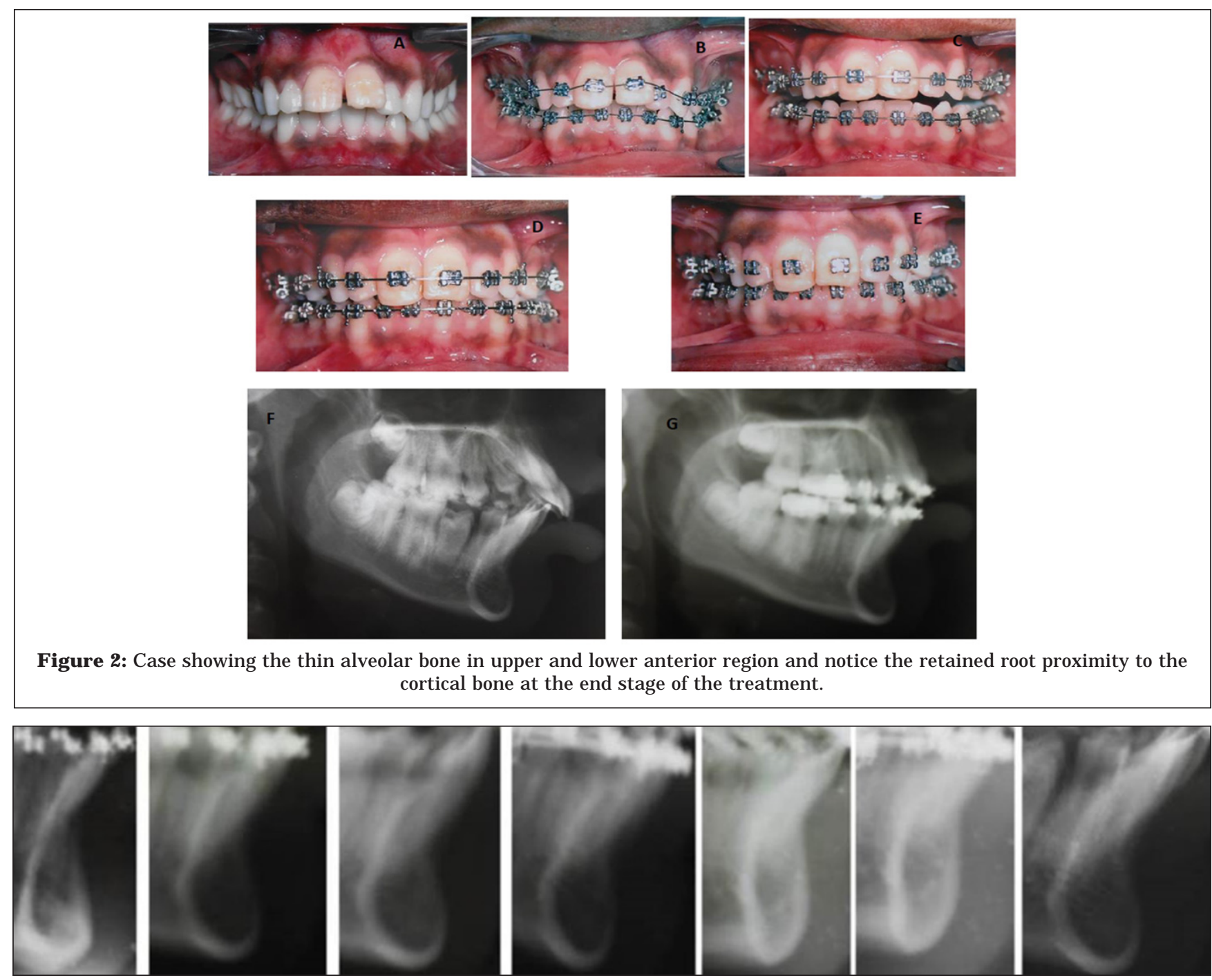

Figure 3: Mandibular alveolar bone depicting the chances of Wash Board Appearance 
Table 1: Sagittal and vertical parameters

\begin{tabular}{lcc} 
SI.No & Parameter & Mean \\
\hline 1. & SNA & 820 \\
\hline 2. & SNB & 800 \\
\hline 3. & ANB & 20 \\
\hline 4. & AO-BO & $1 \mathrm{~mm}$ \\
\hline 5. & SN-MP & 320 \\
\hline 6. & FMA & 250 \\
\hline 7. & Y- AXIS & 59.40 \\
\hline
\end{tabular}

Table 2: Number of subjects in nine subgroups defined by Angle classification and mandibular divergence SN-MP $(\mathrm{N}=100)$

\begin{tabular}{lccc} 
Malocclusion & Low & Average & High \\
Class I & 25 & 14 & 12 \\
\hline Class II & 20 & 10 & 15 \\
\hline Class III & 3 & 0 & 1 \\
\hline P $=0.588$ (NS) & & &
\end{tabular}

Table 3A: Width and Height of anterior alveolus for different malocclusion groups.

\begin{tabular}{lccc} 
Variable & $\begin{array}{c}\text { Class I } \\
\mathbf{N = 4 5}\end{array}$ & $\begin{array}{c}\mathbf{N}=51 \\
\text { Class III }\end{array}$ & $\begin{array}{c}\text { Class II } \\
\mathbf{N = 4}\end{array}$ \\
UAH & $6 \pm 1.1$ & $6.4 \pm 3.1$ & $7.4 \pm 1.8$ \\
\hline LAH & $20 \pm 1.9$ & $20.2 \pm 3.4$ & $22.3 \pm 2$ \\
\hline UPAW & $7.4 \pm 2.6$ & $8.3 \pm 3.7$ & $7.8 \pm 2.1$ \\
\hline UAAW & $3.8 \pm 0.5$ & $4.6 \pm 2.2$ & $4.6 \pm 2.1$ \\
\hline LPAW & $4.1 \pm 1.1$ & $4.1 \pm 1.2$ & $2.8 \pm 1.1$ \\
\hline LAAW & $3.1 \pm 1.1$ & $2.2 \pm 2$ & $2.6 \pm 1.3$ \\
\hline
\end{tabular}

Table 3B: P-value for the measured alveolar bone thickness for different malocclusions

Variable Class I/I Class I/III Class II/III

\begin{tabular}{llll} 
UAH & $>0.05$ & $>0.05$ & $>0.05$ \\
\hline LAH & $>0.05$ & $>0.05$ & $>0.05$ \\
\hline UPAW & $>0.05$ & $>0.05$ & $>0.05$ \\
\hline UAAW & $>0.05$ & $>0.05$ & $>0.05$ \\
\hline LPAW & $>0.05$ & $>0.05$ & $>0.05$ \\
\hline LAAW & $<0.05$ & $>0.05$ & $>0.05$
\end{tabular}

$\mathrm{P}<0.05-$ Significant
Table 4A: Width and height of anterior alveolus for different mandibular divergence groups

\begin{tabular}{lccc} 
Variable & $\begin{array}{c}\text { Low } \\
\mathbf{N = 4 8}\end{array}$ & $\begin{array}{c}\text { Average } \\
\mathbf{N = 2 4}\end{array}$ & $\begin{array}{c}\text { High } \\
\mathbf{N = 2 8}\end{array}$ \\
UAH & $4.54 \pm 1.88$ & $6.7 \pm 2.14$ & $8.52 \pm 2.14$ \\
\hline LAH & $17.8 \pm 2.67$ & $19.6 \pm 3.38$ & $22.6 \pm 2.68$ \\
\hline UPAW & $9.8 \pm 3.5$ & $6.92 \pm 1.86$ & $6 \pm 2.15$ \\
\hline UAAW & $3.9 \pm 1.97$ & $4.2 \pm 1.73$ & $4.8 \pm 1.34$ \\
\hline LPAW & $5.42 \pm 1.76$ & $4.1 \pm 1$ & $3 \pm 1$ \\
\hline LAAW & $3.1 \pm 1.7$ & $2.8 \pm 1.6$ & $2 \pm 1$ \\
\hline
\end{tabular}

Table 4B: P-value for the measured alveolar bone thickness in different mandibular divergence groups

\begin{tabular}{lccc} 
Variable & $\begin{array}{c}\text { Class Low/ } \\
\text { Average }\end{array}$ & $\begin{array}{c}\text { Low/ } \\
\text { High }\end{array}$ & $\begin{array}{c}\text { Average/ } \\
\text { High }\end{array}$ \\
UAH & $\varangle 0.001$ & $<0.001$ & $<0.01$ \\
\hline LAH & $\varangle 0.05$ & $\varangle 0.001$ & $<0.001$ \\
\hline UPAW & $\varangle 0.001$ & $<0.001$ & $>0.05$ \\
\hline UAAW & $>0.05$ & $>0.05$ & $>0.05$ \\
\hline LPAW & $\varangle 0.01$ & $\varangle 0.001$ & $<0.05$ \\
\hline LAAW & $>0.05$ & $\varangle 0.05$ & $>0.05$ \\
\hline
\end{tabular}

$\mathrm{P} \varangle 0.05$ - Significant

orthodontically would retain the root prominence after finishing the treatment (Figure 3). ${ }^{17,18}$

The long term prognosis of such finished cases reported in the literature is scanty. 8, 19, 20 Nevertheless, the reported cases have shown the deleterious effects like root resorption and the gingival recession. As for the normal physiology goes the roots have to get resorbed in the long run because of the proximity to the alveolar bone and the friction between the two hard surfaces. But the question is does it really happen? If so, longitudinal studies should be conducted to check the prognosis of such cases. Bone remodeling is a boon in disguise for the orthodontist, because the bone remodels-the tooth moves. But the earlier studies have shown the limitation to this remodeling processes when the tooth touches certain anatomical limit..-4 Thus, it is wise to go for the interdisciplinary approach like ortho-surgical approach or ortho-perio approach to treat such cases. 
The results of the present study indicate that the alveolar bone thickness was not significantly different in different malocclusion groups except for the lower anterior alveolar bone width (LACW) which was significantly different for the class I and class II malocclusion groups. The lower posterior alveolar bone thickness in the class I malocdusion group was more in comparison to the class II malocclusion group. In class III malocclusion group the measurements like upper alveolar bone height and the lower alveolar bone height were increased in comparison to the other two malocclusion groups. Similar line of findings was reported in the previous study. ${ }^{8}$ Nevertheless contrasting results have also been reported, where they demonstrated significant differences between all the variables among the class I , class II and class III groups except for the anterior and posterior width of the lower anterior alveolus in the class III group. ${ }^{21,22}$ The earlier study on the cephal ometric norms for alveolar bone in the Saudi population, reported that the Saudi people had tendency towards thinner alveolus with increased proclination and protrusion of upper and lower incisors. When the results of the present class I group was compared with the Saudi people, it was found that the upper anterior and posterior alveolar width was more in the Saudi people. ${ }^{22}$

Upper posterior alveolar bone thickness was more in class II malocclusion group than the class I and class III group. This doesn't come as surprise as maxilla will be prominent in the class II malocclusion cases. I $n$ the present study gender-wise difference was not taken into account, but in the previous study on the gender-wise difference for the alveolar bone thickness it was reported that there existed significant difference between males and females in all the malocclusion types. ${ }^{21,22}$

Highly significant difference was noted for the height of the upper alveolar bone and the upper posterior alveolar bone thickness between the low and average mandibular divergence groups, where, the upper alveolar height was less and the upper posterior width was more in the low angle cases. Similar results were reported by Handelman, who reported lesser incidence of narrow alveolar bone in low angle cases in different types of malocdusion groups. $^{8}$

However, for the low and high mandibular divergence groups, highly significant difference $(\varangle 0.001)$ was found for the upper and lower alveolar bone height; the upper and lower posterior alveolar bone thickness. Contrastingly, for the average and high mandibular divergence group the highly significant difference was noted only for lower alveolar bone height. In the low mandibular divergence group, there was increase in the width alveolar bone at upper and lower posterior region, whereas in the high angle cases, increase in the height of the alveolar bone was noted in both the upper and lower region and the results were in accordance to the previous reports of the similar studies. Contrasting results are also been reported, where there existed no significant difference for the alveolar bone thickness for different mandibular divergence groups. ${ }^{23}$

Beckmann et al, in their study on the alveolar bone morphol ogy of maxilla and mandiblein thelong face patients, reported that the mandibular midsagittal alveolar bone in the incisal region has limited anteroposterior dimensions and they advise to restraint antero-posterior movements of these teeth in long-faced patients. ${ }^{24}$ Same can be concluded in the present study as the lower anterior and posterior alveolar width was less in high angle cases.

The key to successful correction malocclusion with thin alveolar bone is following the interdisciplinary approach like going for the selective alveolar decortication (SAD) or periodontally accelerated osteogenic orthodontics (PAOO) technique or else orthognathic surgeries. ${ }^{17}$, 18, 25 The former two techniques don't rely on the existing alveolar bone thickness.

\section{Conclusion}

The alveol ar bone thickness varies according to the pattern of mandibular divergence in the present group of population. The type of malocclusion although influence the morphology of the alveolar bone, but to a lesser extent. The evidence provided can be enhanced by doing thesimilar kind of studies using advanced imaging technique and there existed a scope to check the difference between male and females for the anatomy of the alveolar bone.

\section{Reference}

1. Proffit WR, Ackerman J L. Diagnosis and treatment planning. In: Graber TM, Swain BF, eds. Current Orthodontic Concepts and Techniques, $3^{\text {rd }}$ ed. St Louis: MO Mosby; 1982; 3-100.

2. Horiuchi A, Hotokezaka H, Kobayashi K. Correlation between cortical plate proximity and apical root resorption. Am J Orthod Dentofac Orthop 1998; 114:311-8. 
3. Mulie RM, Hoeve AT. The limitations of tooth movement within the symphysis, studied with laminagraphy and standardized occlusal films. J Clin Orthod 1976; 10:882-93.

4. Sarikaya S, Haydar B, Ciayer S, Ariyrek M. Changes in alveolar bone thickness due to retraction of anterior teeth. Am J Orthod Dentofac Orthop 2002; 122:15-26.

5. Demir A, Uysal T, Sari Z, Basciftci FA. Effects of camouflage treatment on dentofacial structures in Class II division 1 mandibular retrognathic patients. Eur J Orthod 2005; 27:524-31.

6. Wonglamsam P, Manosudprasit M, Godfrey K. Facio-lingual width of the alveolar base. Aust Orthod J 2003; 19:111.

7. Bills DA, Handelman CS, BeGole EA. Bimaxillary dentoalveolar protrusion: traits and orthodontic correction. Angle Orthod 2005; 75:333-9.

8. Handelman CS. The anterior alveolus: its importance in limiting orthodontic treatment and its influence on the occurrence of iatrogenic sequelae. Angle Orthod 1996; 66:95109.

9. Vardimon AD, Oren E, Ben-Bassat $Y$. Alveolar bone remodeling/tooth movement ratio during maxillary incisor retraction with tip versus torque movements. Am J Orthod Dentofac Orthop 1998; 114:520-9.

10. J anson G, Bombonatti R, Brandão AG, Henriques J FC, de Freitas MR. Comparative radiographic evaluation of the alveolar bone crest after orthodontic treatment. AmJ Orthod Dentofacial Orthop 2003; 124:157-64.

11. Mostafa YA, EI Sharaby FA, EI Beialy AR. Do alveolar bone defects merit orthodontists' respect? World J Orthod 2009; 10:16-20

12. Bollen A, Cunha-Cruz J , Bakko DW, Huang GJ , Hujoel PP. The effects of orthodontic therapy on periodontal health: a systematic review of controlled evidence. J Am Dent Assoc 2008; 139:413-22.

13. Yared KFG, Zenobio EG, Pacheco W. Periodontal status of mandibular central incisors after orthodontic proclination in adults. Am J Orthod Dentofacial Orthop 2006; 130:1-8.

14. Allais D, Melsen B. Does labial movement of lower incisors influence the level of the gingival margin? A case-control study of adult orthodontic patients. Eur J Orthod 2003; 25:343-52.

15. Greenbaum KR, Zachrisson BU. The effect of palatal expansion therapy on the periodontal supporting tissues. Am J Orthod 1982; 81:12-21.

16. Rungcharassaeng K, Caruso J M, Kan J Y, Kim J , Taylor G. Factors affecting buccal bone changes of maxillary posterior teeth after rapid maxillary expansion. Am J Orthod Dentofacial Orthop 2007; 132:428.

17. Wilcko MT, Wilcko WM, Bissada NF. An Evidence-Based Analysis of Periodontally Accelerated Orthodontic and Osteogenic Techniques: A Synthesis of Scientic Perspectives. Semin Orthod 2008; 14:305-16.

18. Murphy NC. In vivo tissue engineering for orthodontists: a modestrst step, in Davidovitch Z, Mah J , Suthanarak S (eds): Biological Mechanisms of Tooth Eruption, Resorption and Movement. Boston, Harvard Society for the Advancement of Orthodontics 2006:385-410.

19. Artun J, Krogstad O. Periodontial status of mandibular incisors following excessive proclinations. A study in adults with surgically treated mandibular prognathism. Angle Orthod 1987; 47:293-9.

20. Kaley J, Philips C. Factors related to root resorption in edgewise Practice. Angle Orthod 1991; 61:125-32.

21. Adela AlHadlaq. Anterior alveolar dimensions among different classifications of sagittal jaw relationship in Saudi subjects. Saudi Dent J 2010; 22(2):69-75.

22. Al-Barakatia S, Alhadlaqa A. Anterior alveolar dimensions in Class I Saudi subjects. J Pak Dent Ass 2007; 16:95-102

23. Edwards J G. A study of anterior portion of the palate as it relates to orthodontic therapy. Am J Orhtod 1976; 69: 24973.

24. Beckmann SH, Kuitert RB, Prahl-Andersen B, Segner D, Tuinzing DB. Alveolar and skeletal dimensions associated with lower face height. Am J Orthod Dentofacial Orthop 1998; 113:498-506.

25. Wilcko WM, Ferguson DJ, Bouquot J E, Wilcko MT. Rapid orthodontic decrowding with alveolar augmentation: case report. World J Orthod 2003; 4:197-205.

\section{Gain quick access to our journal online View our journal at www.nacd.in}

